\title{
Fluyen nuevos órdenes entre mujeres, aguas y territorios en el borde urbano-rural del sur de Bogotá ${ }^{1}$
}

\section{Flowing new orders between women, waters and territories on the urban-rural edge of southern Bogotá}

\author{
Dolly Cristina Palacio Tamayo \\ Universidad Externado de Colombia, Bogotá, Colombia. \\ dolly.palacio@uexternado.edu.co|https://orcid.org/0000-0001-9749-1237
}

\section{Andrea Marcela Arrieta Narváez}

Fundación Alianza Biocuenca, Fondo del Agua de Norte de Santander, Pamplona, Colombia. marcela.arrieta@gmail.com | https://orcid.org/0000-0002-8824-8793

Recibido: 2 de diciembre de 2019. Aprobado: 8 de junio de 2020 .

DOI: 10.25100/lamanzanadeladiscordia.v15i1.10473

Artículo de investigación

¿Cómo citar este artículo? / How to quote this article?

Palacio, Dolly Cristina, y Arrieta, Andrea Marcela. (2020). Fluyen nuevos órdenes entre mujeres, aguas y territorios en el borde urbano-rural del sur de Bogotá. La Manzana de la Discordia, 15(1), 1-31. doi: 10.25100/lamanzanadeladiscordia.v15i1.10473

\footnotetext{
${ }^{1}$ El presente artículo es producto del proyecto financiado por Colciencias, convocatoria 569 de 2012 , Territorios del agua y redes de práctica y aprendizaje. Apropiación social del conocimiento para la gestión colaborativa del borde sur del D.C. Contrato 0414- 2013, Colciencias-Universidad Externado de Colombia. Realizado entre 2013 y 2017.
} 
Fluyen nuevos órdenes entre mujeres, aguas y territorios en el borde urbano-rural del sur de Bogotá

Quiero volver a tierras niñas; llévenme a un blando país de aguas. En grandes pastos envejezca y haga al río fábula y fábula. Tenga una fuente por mi madre y en la siesta salga a buscarla, y en jarras baje de una peña un agua dulce, aguda y áspera. Me venza y pare los alientos el agua acérrima y helada. ¡Rompa mi vaso y al beberla me vuelva niñas las entrañas!

Fragmento del poema "El agua" de Gabriela Mistral.

\title{
Resumen
}

Una perspectiva histórica, relacional y feminista nos permite reconocer cómo los vínculos de cuidado y de gestión comunitaria del agua, con un importante liderazgo de las mujeres, trascienden un emprendimiento o el trabajo como escenario de empoderamiento social. Estos vínculos se actualizan y se transforman, aportando al fortalecimiento de las capacidades de los territorios en pos de un derecho al agua y la sostenibilidad territorial. En este artículo, se reconocen y analizan las prácticas de un conjunto de mujeres que lideran procesos de gestión comunitaria del agua en el borde urbano rural del sur de Bogotá. Identificamos, desde el análisis de las relaciones comunitarias e institucionales, que las mujeres construyen a partir de estrategias de colaboración y gestión del agua, nuevos vínculos que le agregan valor al territorio al movilizar proyectos que articulan buenas prácticas con el agua, la tierra, el alimento y las tecnologías; y mantienen espacios sociales para acordar las reglas formales e informales que ordenan el uso del agua, construyendo un tejido socioambiental que aportan a los procesos que mantienen la cantidad y calidad del agua. Procesos que aportan a la sostenibilidad de un territorio que contiene los embalses de abastecimiento de agua potable para cerca de 2’000.000 de habitantes del sur de Bogotá.

Palabras clave: Agua; Ecofeminismo; Acueductos comunitarios; Perspectiva histórica y relacional; Bogotá.

\begin{abstract}
An historical, relational and feminist perspective allows us to recognize how women roles of care and community management of water, with an important leadership that goes beyond entrepreneurship or work as a stage of social empowerment, are updated and transformed, in order to contribute to the strengthening of social capacities of the territories to pursuit rights to water and sustainability. With this paper we identify and analyse a set of practices of a group of women
\end{abstract}


who lead community water management processes in the rural urban edge of southern Bogotá. We, recognize within the analysis that women build, from collaboration strategies and water management, new values that they add to the territory by mobilizing good practices with water, land, food production and technologies; they also maintain social spaces to make agree about rules and regulations that organize the use of water, they build a socio-environmental tissue that contributes to maintain water quantity and quality, which in turn contribute to the sustainability of a territory that contains the reservoirs to supply drinking water to nearly 2,000,000 inhabitants of southern Bogotá.

Keywords: Water; Ecofeminism; Community Aqueducts; Historical and Relational Perspective; Bogotá.

\section{Introducción}

Este artículo es uno de los resultados de una experiencia de investigación colaborativa entre actores de la academia, la empresa pública y las organizaciones sociales ${ }^{2}$, sobre los procesos de conformación de los Acueductos Comunitarios (AC) y su papel en la gestión social del territorio del borde urbano-rural de Bogotá $^{3}$ (Palacio, Van der Hammen y De Urbina, 2018). En esta investigación, emerge, de manera evidente, la preponderancia del papel de las mujeres, sin ser ellas las únicas ni las más visibles en la gestión comunitaria del agua de este territorio. Alineadas con nuestra propia posición como mujeres investigadoras y habitantes de Bogotá, y comprometidas con la construcción de una conciencia ecológica situada, implicada y propia, vemos la necesidad de nutrir la reflexión sobre el papel de las mujeres y su injerencia en la construcción emergente de un ecofeminismo que propone nuevos órdenes en las relaciones con el agua y el territorio (Haraway, 1995; Puleo, 2011, 2019; Ulloa, 2015, 2016; Neimanis, 2017; Celiberti, 2019). Órdenes que reconocen nuestra pertenencia a los procesos de la vida en La Tierra, que reconoce la función ecológica y social del agua en territorios donde las urbes modernizantes del neoliberalismo globalizador crecen arrasando con otros modos de existencia

\footnotetext{
${ }^{2}$ El proyecto fue financiado por Colciencias, convocatoria 569 de 2012 Territorios del agua y redes de práctica y aprendizaje. Apropiación social del conocimiento para la gestión colaborativa del borde sur del D.C. Contrato 04142013, Colciencias-Universidad Externado de Colombia. Realizado entre 2013 y 2017.

${ }^{3}$ Bogotá D.C. es una entidad territorial constituida por una zona urbana y una rural, que en conjunto comprende 164.000 ha.
} 
que tejen la vida de otras maneras; formas que pueden asegurar la sostenibilidad ambiental y ecológica de estas urbes y los territorios donde se instauran.

El entrecruce de la acción comunitaria y profesional de dos grupos de mujeres, las líderes comunitarias rurales y las profesionales urbanas que acompañan los procesos de gestión comunitaria del agua en los espacios de transición del borde-urbano rural de Bogotá Distrito Capital, durante los últimos 40 años, evidencian importantes transformaciones en los roles de género en relación con el agua y el territorio. Estas transformaciones incluyen el desarrollo de motivaciones, intereses y acciones de estas mujeres que han mostrado una gran capacidad para integrar, en escenarios de colaboración, a otros líderes relacionados con la defensa de los derechos colectivos, como son el derecho humano al agua, la defensa del agua como bien común y la defensa de los territorios campesinos. Ellas, además, articulan y posibilitan diálogos colectivos para la defensa de ecosistemas asociados a las fuentes de agua como los páramos, ecosistemas base de la vida en el territorio.

El papel de las mujeres en la gestión comunitaria del agua en la literatura de los estudios feministas ha crecido de manera importante en las últimas décadas en Latinoamérica. Estos estudios evidencian, principalmente, un creciente interés en los campos del derecho humano al agua, los conflictos ambientales relacionados a disputas entre usos comunitarios y prácticas extractivistas, así como la cultura del agua, priorizando ámbitos rurales o territorios étnicoculturales (Ulloa, 2016; Arriagada y Zambra, 2019; Delbene-Lezama, 2019).

Desde finales de los años 90 del siglo XX y principios del XXI (Rocheleau, ThomasSlayter y Wangari, 1996, 2004; Shiva, 1997) ya reconocían distintas perspectivas del feminismo relacionado con la ecología. En particular, Rocheleau et al. (1996) hacían diferencia entre el ecofeminismo y la ecología política feminista para comprender la relación género/naturaleza/cultura. En particular, el ecofeminismo, dicen estas autoras, suele establecer una perspectiva esencialista, donde existe una particularidad del ser femenino, afianzando roles tradicionales asociados a la naturaleza y, por ende, más propenso a su cuidado y protección. Por el contrario, el segundo, se define como un enfoque que se deriva de los estudios feministas de la ecología cultural, los desarrollos de la ecología política, la geografía feminista y la economía política. Su foco está en el tratamiento del género como una variable crítica que da estructura al acceso y al control sobre los recursos naturales, configurando los procesos del cambio ecológico, la lucha de hombres y mujeres por mantener sus modos de vida viables y la perspectiva de una 
comunidad basada en los principios del desarrollo sostenible.

Desde la perspectiva Latinoamericana, se esgrimen otros enfoques que muchas veces conectan con la primera y otros con la segunda (Ojeda, 2012; Ulloa, 2016; Celiberti, 2019), pero también emergen feminismos propios, muchas veces articulados con movimientos sociales de los pueblos originarios de América, con un enfoque de arraigo y tradición que a su vez cuestiona el papel de las mujeres y sus propias formas de reivindicar su poder y participación (Siderac, 2019). Ulloa (2016) ha referenciado estos últimos como los feminismos autónomos o comunitarios y los feminismos territoriales.

Ahora bien, no obstante, es importante reconocer que las mujeres son agentes claves en la construcción de nuevos órdenes sociales, culturales y ecológicos. Muchas de estas tesis continúan manteniendo una dualidad cultura/naturaleza entre los géneros, como si entre ellos unos fuesen más cercanos a la naturaleza, y otros, más distantes o separados de ella. Al igual, dichas posturas permanecen en un dualismo epistémico, donde los humanos son sujetos y los no humanos son objetos o recursos.

Intentando ir más allá de esta dualidad, nos unimos a ecofeminismos que pujan por enfoques que, si bien, emergen de estas escuelas feministas y ecologistas, van más allá del género e incluso de lo humano (Haraway, 1995; Neimanis, 2017; Puleo, 2019), para entender que la humanidad y, en particular, las mujeres requieren reconocerse como parte de una especie, y su consecuente pertenencia al entramado de la vida en La Tierra. Especie humana que, por ser tal, no pierde sus atributos particulares, incluyendo el lenguaje, sus modos de vida culturales, la perspectiva histórica, sus economías, las formas políticas y las relaciones de poder que gobiernan sus territorios y sus poblaciones.

A partir de estos feminismos, nos sintonizamos con la relevancia de transcender la visión dualista de naturaleza/cultura, pero también ir más allá de la visión holista y biologisista de la ecología profunda (Haraway, 1995; Neimanis, 2017; Puleo, 2019; Celiberti, 2019) que prescinde incluso del ser humano para preservar la vida. Feminismos que se abren hacia una consciencia ecológica para crear nuevos órdenes. Órdenes donde los humanos y, en particular, las mujeres somos seres capaces de proponer interpretaciones novedosas de los vínculos que hemos construido con la Tierra. Vínculos que cultural e históricamente hemos tergiversado, tanto a partir de los imaginarios y prácticas tradicionales, como a partir de las prácticas asociadas al 
orden occidental modernizante del neoliberalismo globalizador contemporáneo que, entre otras, ha llevado a La Tierra a una trasformación que ha tenido efectos sobre los diversos contextos ambientales, llevando a la biosfera a una crisis sin precedentes (Latour, 2017).

Este es un ecofeminismo que plantea que las mujeres desde sus modos de existencia se vinculan y proponen roles activos y propositivos, planteando nuevos acuerdos para instaurar nuevas prácticas, nuevos entramados, nuevos órdenes de la vida. En este marco, las mujeres hacen negociaciones situadas que agregan valor a las dinámicas socio-ecológicas. Es decir, este es un ecofeminismo que propone nuevos pactos entre hombres y mujeres, entre humanos y no humanos; un ecofeminismo que quiere superar la visión de una humanidad que se ubica por fuera de la naturaleza y actúa como consumidora, productora extractiva y tomadora de decisiones sobre y no desde y con la naturaleza (Puleo, 2019).

Nosotras, las autoras, como habitantes de Bogotá, formadas en las disciplinas del Trabajo Social y la Antropología, fuimos y aun somos partícipes de espacios de colaboración con un conjunto de mujeres habitantes de la ruralidad, lideresas vinculadas a la gestión comunitaria del agua en el sur de Bogotá. Con ellas construimos un diálogo permanente que articula el trabajo continuo y comprometido de un conjunto de mujeres urbanas, profesionales que acompañan los procesos sociales con fuertes lazos sociales y ecológicos que van encaminados a la construcción de un ecologismo popular, feminista e implicado con y desde el agua, entendida como el elemento fundador y fundamental del tejido de la vida y el territorio.

En este sentido, al ubicarnos en el origen de los Acueductos Comunitarios (AC) de Bogotá en la década de 1980, reconocemos un contexto histórico de neoliberalización de la naturaleza y descentralización administrativa, acompañado de frecuentes reivindicaciones de las comunidades organizadas frente a las instituciones, reclamando su derecho al agua y al territorio. En todo este proceso, las mujeres tuvieron un importante papel, ya que estas lideresas hablaron en nombre de sus comunidades y negociaron con las instituciones para la construcción de las primeras infraestructuras que permitieron llevar el agua a sus hogares.

Al mismo tiempo, un conjunto de funcionarias de las instituciones nacionales, regionales y municipales con múltiples vínculos con el territorio, la comunidad y el agua, preocupadas por garantizar el desarrollo de las comunidades a través del abastecimiento universal de agua para consumo humano, acompañaron la construcción y mantenimiento, no solo de las infraestructuras, 
sino de la organización social y comunitaria para su gestión integral, haciendo de puente entre instituciones, técnicos, en su mayoría hombres, y los líderes y usuarios de las comunidades que recibieron dichas infraestructuras para su manejo local.

En particular, aquí construimos una versión de esta historia a partir del análisis de doce relatos de un conjunto de seis lideresas comunitarias y seis funcionarias públicas, que han participado en el proceso de establecimiento y consolidación de los AC entre 1982-2017. El análisis lo hacemos tomando como punto de partida la historia de vida de Dilia, lideresa del Acueducto del Destino en Usme, cuyo nacimiento e infancia están marcados por la obra del primer acueducto moderno de Bogotá en la década de 1930 y cuya obra desplazó a su familia de la parte alta del entonces municipio de Usme hacia una vereda más cercana al casco urbano. Las historias y experiencias de vida de estas mujeres se van entrelazando, entre ellas y el territorio, donde se ve claramente como emergen nuevos significados en relación con el agua y con sus propios roles, proponiendo nuevos proyectos de vida, en los que su actuar cotidiano con el agua, la vida y el territorio son elementos que guían su militancia y sus estrategias de acción, que además se combinan con los marcos normativos y de la planeación del desarrollo de manera estratégica.

Para cumplir nuestro objetivo, en este artículo proponemos dos partes. La primera señala aspectos de la fundación de una hegemonía moderna del abastecimiento urbano del agua en Bogotá, donde el territorio, la comunidad y las mujeres están ausentes. Esta historia contrasta con la segunda parte del artículo que presenta la versión de lideresas comunitarias y mujeres profesionales funcionarias de las instituciones distritales, quienes narran otra historia del abastecimiento del agua. En esta narración reconocimos relaciones entre estas mujeres y sus existencias urbanas y rurales, donde se reconocen dificultades, inestabilidades y fragilidades que enfrenta la colaboración entre actores heterogéneos humanos y no humanos para instaurar los nuevos órdenes y sus desafíos para estabilizar la permanencia de estos nuevos vínculos que pretenden ser ecológicamente sostenibles con el agua y el territorio. Finalmente, a manera de conclusión, se subrayan algunos puntos como pistas para pensar en nuevos órdenes más orgánicos y comunitarios, como principio fundamental de una sostenibilidad territorial en la que los seres humanos hacemos parte integral del tejido de la vida que los construye. 


\section{Apuntes de la fundación de una hegemonía moderna sobre los territorios que abastecen de agua a Bogotá, un relato con ausencia de lo femenino}

Desde comienzos del siglo XX, el agua ha servido como vínculo en la ciudad de Bogotá, entre sus territorios urbanos y rurales, que incluye los antiguos municipios de Usme y Bosa (Osorio, 2007, 2008; Rodríguez, 2003; Palacio y Rouillón, 2008; Preciado, Leal y Almanza, 2005). Esta es una historia donde priman los agentes y las instituciones del Estado como protagonistas de la construcción de infraestructuras que modernizan las formas de vivir.

Las necesidades de los habitantes urbanos de Bogotá y los ideales de una ciudad moderna que se abastece a través de un acueducto centralizado se impusieron sobre las necesidades de la población local del borde sur y sobre la relación de estos habitantes con sus fuentes locales de agua, como veremos a continuación. A partir de la década de 1930, el ideal moderno del desarrollo urbano y la planeación influenciaron la expansión de la construcción de Bogotá y reafirmaron el orden segregador centro-periferia, presente en este territorio desde la Colonia, que marca la forma de interpretar los asentamientos de la población indígena y luego de las poblaciones inmigrantes (Del Castillo, Urrea y Montaña, 2011; Rodríguez, 2003).

Dentro de esta historia solo es posible seguir los desarrollos relacionados con el abastecimiento de acueducto y alcantarillado de la población urbana y cómo afectan estos el desarrollo del borde sur, porque no existe suficiente información sobre las formas de abastecimiento de la población rural en publicaciones sobre el desarrollo urbano y/o la historia ambiental de la ciudad. Este hecho subraya la segregación estructural a la que se enfrenta esta población en donde sus versiones, visiones y narraciones no son tenidas en cuenta en la historia de la construcción de su territorio (Arrieta, 2018).

A finales del siglo XIX y comienzos del XX, el proyecto de la modernidad se vio fuertemente influenciado por los desarrollos de nuevas tecnologías que tuvieron como fin la modernización a través del control de los recursos naturales (Kaika, 2005). Al final del siglo XX y como reacción a los desastres naturales y el estado de degradación de la naturaleza, se cuestionó el proyecto de la modernidad. Los ecosistemas se vieron potencialmente en peligro y la contaminación del ambiente como un obstáculo para el desarrollo de la sociedad (Kaika, 2005). Estas tendencias se vieron reflejadas en la historia de Usme y Ciudad Bolívar — dos localidades de Bogotá- y sus fuentes de agua, pero no de forma uniforme en todo su territorio 
(Rodríguez, 2003; Osorio, 2007, 2008).

La división instrumental entre lo rural y lo urbano en el marco de la planeación del territorio, dividió también la oferta de servicios públicos que quedaban circunscritos a lo urbano, lo que se definió a partir de normativas que delimitaron estos territorios (García y Cortés, 2018), cuando estos asentamientos, en particular ciudades como Bogotá estuvieron en una dinámica permanente de crecimiento formal e informal, transformando suelo rural en urbano y deteriorando tanto las fuentes de agua como los suelos al servicio de demandas del mercado inmobiliario (Jaramillo, 2014).

Esta historia, contada desde los actores institucionales, desconoce completamente las dinámicas de los sistemas productivos, la tenencia de la tierra y las prácticas sociales y culturales en torno al agua en territorios que estaban viviendo estas transformaciones tan fuertes, como eran estos bordes urbano-rurales (Van der Hammen, Morales, Gómez, Rodríguez, Cuervo, Aya, León, 2018).

Para terminar, las narrativas de esta historia de construcción de infraestructuras y los procesos de organización de estos servicios, no contemplaron a los actores directos del territorio rural, lugar por excelencia de las intervenciones que hacen las captaciones de agua, sin mostrar una retribución ecológica ni social a los habitantes de los territorios donde se capta el agua para la ciudad (Van der Hammen, Cano y Palacio, 2015; Palacio et al., 2018).

Estas narrativas sobre la modernización del territorio, se sitúan en la agencia de los líderes de alto nivel como son los presidentes, los alcaldes mayores, las instituciones públicas que ellos representan y los aportes de entidades internacionales que desde calendarios globales aportan presupuestos para la modernización del país. Por ejemplo, la producción de agua potable para la población urbana ha estado siempre al frente de las preocupaciones de la administración nacional y luego distrital; en cambio, la gestión de las aguas servidas y la consecuente contaminación de los ríos ha sido descuidada con poca inversión (Osorio, 2007; 2008; Rodríguez, 2003; Sánchez, 2016).

Este hecho ha damnificado a gran parte de la población que, siendo habitantes del borde sur, viven junto a las fuentes y territorios afectados por la captación de sus aguas y su contaminación, siendo estos partes de sus paisajes, historias y fuentes de abastecimiento cotidiano (Sánchez, 2016). La inminente contaminación de las fuentes de agua y los reclamos de la población local fuerzan a las instituciones municipales a construir sistemas de alcantarillado 
y de tratamiento de aguas servidas que, con lentos avances, buscan desmarginalizar a la población afectada (Osorio, 2007, 2008), y con presupuestos muy puntuales buscan establecer sistemas de abastecimiento rural (Palacio et al., 2018).

Estos programas, proyectos e informes de gestión, promovidos desde los agentes visibles de los gobiernos, son relatos insuficientes de lo que verdaderamente sucede en los territorios. Las comunidades organizadas y en particular un trabajo importante de sus lideresas y funcionarias — quienes muchas veces no están en cargos principales-, son la clave de la construcción de vínculos que permiten establecer continuidad del cuidado del agua y de las fuentes en el territorio.

Este es el papel multidimensional de las mujeres (Beall, 1995) que, como habitantes, están a cargo de labores de reproducción y crianza, de cuidado de adultos mayores en los espacios domésticos, de la alimentación y el uso eficiente y ahorro del agua, no solo a nivel domiciliario sino a nivel de las unidades productivas agropecuarias. Así mismo, ellas son trabajadoras en las faenas del campo y agentes principales de los proyectos productivos alternativos como son el turismo comunitario y su liderazgo social (Cuervo, Van der Hammen y Morales, 2018).

Este entramado socioambiental entre las mujeres y el agua, desde el caso del borde urbano-rural del sur de Bogotá, es el eslabón invisible de la sostenibilidad territorial. La cooperación de las mujeres en la construcción de AC, sistemas que hoy en día garantizan el agua tratada a la población de Ciudad Bolívar, Usme y Sumapaz y su participación en la configuración de sistemas productivos que buscan defender el territorio y la vida, así como mantener las fuentes vivas que lo permiten, es la muestra de que el logro de mantener estrategias de gestión comunitaria del agua en los territorios agrega valor a la economía local y regional desde una perspectiva de sostenibilidad ecológica y social. La protección de estas fuentes además garantiza que los embalses de Chisacá y La Regadera continúen abasteciendo de agua potable alrededor de dos millones de habitantes del sur de Bogotá (Palacio et al., 2018).

\section{Trayectorias personales, cruces, conexiones entre lideresas comunitarias y funcionarias institucionales}

En esta sección presentamos el entrecruce de la acción de doce mujeres: seis lideresas de las Juntas Administradoras de las Asociaciones de Usuarios de los AC y seis funcionarias de diversas instituciones que hacen planeación, gestión y regulación del agua en el sur de Bogotá. Desde finales de la década de 1970, las lideresas fueron estableciendo un entramado de interacciones 
entre ellas y las instituciones que intervienen el territorio, con el objetivo de garantizar el acceso colectivo al agua para los habitantes de la ruralidad del sur de Bogotá. Acceso al agua que en un principio fue asegurado por la hacienda agraria y los sistemas de acequia, que se aprovecharon las fincas y los campesinos de la región mediante un sistema de acceso por mangueras, o por medios de recolección con canecas con la ayuda de burros y otros semovientes directamente desde la fuente. Al mismo tiempo, los gobiernos de Bogotá y sus instituciones, que desde comienzos del siglo XX estudiaron y explotaron sus fuentes para abastecer a la población urbana, desplazaron a sus familias, contaminando sus ríos y alterando sus ecosistemas, como se puede observar en la Figura 1 .

Fuente: Proyecto Territorios del Agua. UEC - Colciencias, 2013-2017.

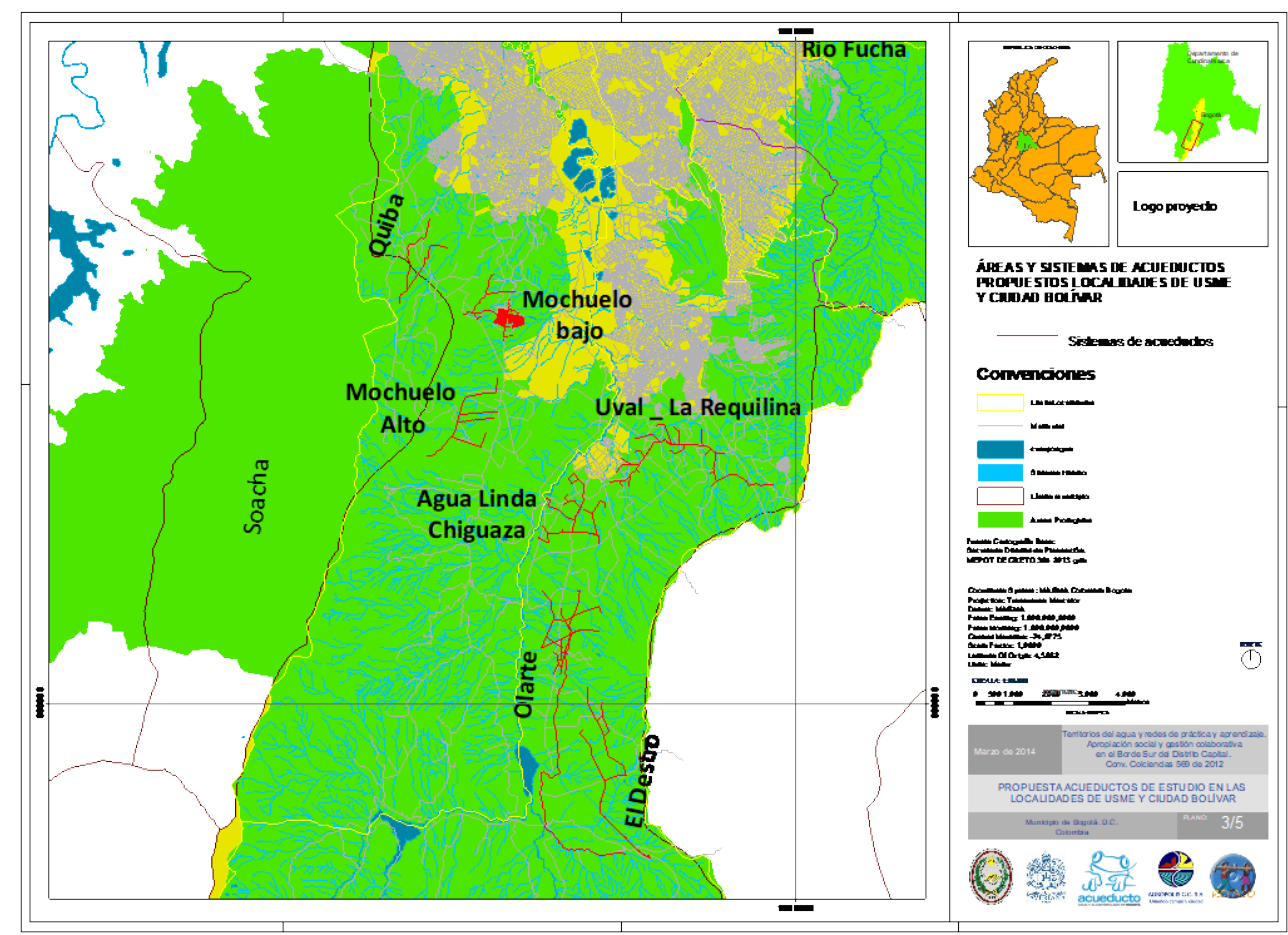

Figura 1. Acueductos Comunitarios seleccionados en su contexto urbano-rural.

\subsection{Lideresas comunitarias conectando versiones de la gestión del agua y construyendo puentes de conocimiento}

A continuación, exponemos un entramado de acciones e interacciones de mujeres que desde los años 80 del siglo XX hasta la segunda década del XXI, han participado y continúan participando de la gestión comunitaria del agua en veredas de Usme y Ciudad Bolívar en Bogotá. Las 
reconocemos como una agencia que teje relaciones y cuestiona órdenes hegemónicos, proponiendo nuevos órdenes en los que el agua y la vida fluyen para la población rural.

\section{Nuevos liderazgos femeninos en la ruralidad}

Dilia, nacida en la zona rural de Usme en los años 30 del siglo XX, hija de un líder campesino, asume la dirección de la Junta de Acción Comunal (JAC) de la vereda ${ }^{4}$ el Destino, con la muerte de su padre en la década de 1980. Ella representa el liderazgo de una mujer que es reconocida por ser la primera que gestiona la construcción del primer acueducto rural de la época. Durante este periodo declarado por Naciones Unidas como la década del agua potable, se hacen fuertes intervenciones en infraestructura rural con inversiones de la Banca Internacional mediante proyectos como el DRI-Pan ${ }^{5}$, liderados, en Colombia, por las Corporaciones Autónomas Regionales. Esta lideresa narra cómo asumió la negociación directa de esta infraestructura con la Corporación Autónoma Regional de Cundinamarca $(\mathrm{CAR})^{6}$, mediante el contacto persona a persona y la mediación entre institución y comunidad a través de la traducción de necesidades y expectativas, usando la persuasión para convencer y exigir la satisfacción de las necesidades más básicas de las personas y para proteger el agua. En su relato, ella evidencia una gran habilidad y flexibilidad para adaptarse a un proceso sin instrucciones, además de mostrar cómo el hecho de ser la hija de un líder y mantener una inmensa convicción, energía, trabajo y dedicación, le permitieron acceder a procesos y a personas en un contexto de marginalidad estructural de los habitantes de la ruralidad.

El apoyo de las instituciones ha reafirmado su posición de gestora y líder. Con esta autoridad ella, como gestora del agua, ha buscado contribuir a que la comunidad cuide el agua; pagar por el agua es para ella una forma de regular, de forma equitativa sin explotarla, la fuente a la que se la considera sagrada.

Por su parte, Ana Elfa, quien aprende mucho de Dilia y con quien trabaja mano a mano, lidera en su vereda Las Margaritas, el proceso de construcción de su AC, convirtiéndose en una

\footnotetext{
${ }^{4}$ Las veredas son distritos o zonas en las que se divide el municipio en su área rural.

${ }^{5}$ Desarrollo Rural Integrado y Alimentación.

${ }^{6}$ En ese entonces de los valles de los ríos Bogotá, Ubaté y Suárez. En ese entonces adscrita al Departamento Nacional de Planeación, Departamento Nacional de Planeación -DNP-, cuyo papel planificador a nivel regional se consolidó para las áreas rurales, principalmente.
} 
líder muy reconocida no solo por gestión del agua y su trabajo de fontanería, sino también por el trabajo de promoción cultural y social en la vereda. Ana Elfa se ha adaptado a las incertidumbres apoyándose en personas puntuales de su comunidad. Su gran capacidad de convocatoria y su compromiso constante le otorgan la legitimidad en su entorno y frente a las instituciones. Lejos de la formalización y de conocimientos técnicos, se lanza a probar mecanismos y soluciones de manera experimental. Su flexibilidad para adaptarse a los cambios le permite cooperar con las instituciones y sus tiempos en ocasiones.

Otra experiencia es la de Flor Alba, líder del acueducto de Aacupasa, de la vereda Santa Rosa de Ciudad Bolívar. Esta lideresa estudió en un colegio de monjas en Usme, pero al final validó el bachillerato por radio, y también participó en capacitaciones de enfermería del programa DRI-Pan, ya mencionado anteriormente. Ella cuenta que hereda de su padre, al este enfermarse, el liderazgo en la JAC, y asume también la gestión del acueducto, logrando la formalización del proceso de administración de la Asociación del AC que ella representa. Flor Alba ha mediado en los conflictos entre versiones institucionales y versiones comunitarias sobre el agua y las formas de gestión, Con lo cual ha logrado crear un campo en donde actores enfrentados están dispuestos al diálogo.

Flor Alba utiliza el proceso de formalización del acueducto para hacerlo no solo un sujeto de deberes, sino de derechos que garantiza la legislación. Su conocimiento de la legislación y los procesos le permiten solucionar conflictos favorablemente para el acueducto, frente a instituciones y frente a terceros. Gracias a su cooperación con las instituciones, estas y la legislación se convierten en mediadoras de sus conflictos con la comunidad. Seguir procesos de formalización no significa entonces, en su caso, exponerse a relaciones desiguales de poder, sino que significa empoderarse desde el conocimiento de sus derechos para reclamar por ellos desde una posición legítima e institucional.

En sus narraciones, cada una de las lideresas partieron de sus motivaciones en la organización de la comunidad, de su trabajo con los $\mathrm{AC}$, de las necesidades sentidas de la población y de otras mujeres, quienes, para la alimentación, el aseo de sí mismas y sus familias y el trabajo en el campo, tenían que recorrer largas distancias y pasar trabajos fuertes para conseguir el agua. Al respecto, Ana Elfa comenta: "Antiguamente la gente tenía agua de los chorros de los aljibes, no todos tenían la necesidad [de abastecerse con AC] (...). Una hermana mía, con obreros tenía que llevar el agua en caballos 20 - 30 obreros, en agricultura" (Usme. 
Comunicación personal, 2 de febrero, 2015). Estas eran las condiciones para conseguir agua en la vereda Margaritas, las cuales motivaron la organización de la comunidad para reclamar la construcción de los acueductos para las veredas de Usme.

Dilia también narraba: "El trabajo de la CAR era dejarlo [el punto de abastecimiento] a la entrada de cada finca. Pero yo les dije: No, si el agua va hasta la finca, que llegue hasta la casa, que es donde se cocina, se lava, se hace todo; el doctor apenas se reía" (comunicación personal, 2 de febrero, 2015).

Una de las principales estrategias de las líderes en su gestión es reivindicar el carácter comunitario de los acueductos. Es el caso de Dilia que recupera la confianza de la comunidad en la JAC, invitando a la asamblea con papeletas escritas a mano, persona a persona, acto recompensado y reconocido por la comunidad que la eligen como su representante. Es desde esta posición reivindicada que ella se dirige a las instituciones para reclamar el AC. Esta dinámica se observa también en la gestión de Flor Alba, quien legitima el carácter comunitario de la JAC y de la Asamblea de Usuarios del AC. Haciendo activo su carácter de representante para convocar, Flor Alba reúne a la comunidad para que ellos decidan si quieren independizar la organización del acueducto de las JAC y organizarse en una asociación de usuarios. Camino que va a seguir repetidas veces: "La gente estuvo de acuerdo que se hiciera, se hizo un acta de constitución. Ya después se nombró un comité (gente de la comunidad preparada abogados, contadores etc.) para hacer los estatutos, los elaboramos con la colaboración del asesor Jurídico de la Alcaldía de Usme” (comunicación personal, 24 de noviembre, 2015).

\section{Incertidumbre, flexibilidad, prueba y error}

En un recorrido, Ana Elfa nos mostraba dónde estaban ubicadas las purgas y los desfogues ${ }^{7}$, y nos contaba cómo su trabajo no tenía rutinas: "Yo tengo pensado irme hoy, por ejemplo. Ir y limpiar dos purgas. Pasa y sucede que no, que ese sector amaneció sin agua, entonces toca ir a mirar cuál fue el daño" (comunicación personal, 2 de febrero, 2015). Esa mañana su plan era lavar el tanque de cloración, pero antes de llegar a las estructuras nos alcanzó la camioneta de la Secretaría de Ambiente. Esta vez la improvisación, el cambio de planes se daba porque una institución aparecía de improviso. En ocasiones vimos cómo se hacían citas con las operarias y

\footnotetext{
${ }^{7}$ Nombre de prácticas y procesos de manejo del acueducto.
} 
juntas administradoras, pero este no fue el caso. Ana Elfa les preguntó cuál era el objetivo de su visita. Luego comentó: “¿qué se hace acá en un día de trabajo? un día de trabajo es todo lo que salga en el día". Así que, ese día, mientras hacíamos el reconocimiento del estado de la quebrada, acompañando a la funcionaria de la Secretaría de ambiente, Ana Elfa me siguió contando de las crisis que vivió junto a la comunidad y el acueducto, y cómo las supo sortear. La primera dificultad que experimentó Ana Elfa en la construcción de los $\mathrm{AC}$, se presentó cuando haciendo parte del Comité de Aguas, recibió la noticia de que su acueducto quedó priorizado para ser el primero en ser construido. A pesar de las buenas noticias, Ana Elfa no disfrutó este momento al verse sorprendida por no estar preparada. La gestión y construcción de los acueductos seguía un proceso desconocido para sus participantes:

Con esos problemas del acueducto. Madrúgueme a ver esa hilachita [hilo] de agua. Yo le dije a Dios: consígame a alguien que se dé mañas. A mí me dio por cerrar ese registro de Gutiérrez, yo me fui a ver a mi hijo y esas noches eran noches de Luna. Yo oí ese chorro, yo dije Dios mío, ese acueducto ya se dañó, y apenas veo ahí ese tanque lleno. Yo ya me enloquecí. Por la mañana estaba ese chorrito de agua. Toda la tancada [tanque] de agua. Usted no es capaz de dejarme ir [habla con Dios]. Cerré ese registro y ahora había agua, quiere decir que allá estaba el escape que no dejaba llenar el tanque. Yo empecé a darle agua a todo el mundo y desde ahí inicié (Ana Elfa Zambrano, comunicación personal, 2 de febrero, 2015).

Las líderes de la comunidad quedan con diferentes tareas al frente del funcionamiento del abastecimiento de agua. A partir del testimonio de Ana Elfa, podemos ver cómo la improvisación, en este caso, de cerrar un registro del sistema para probar si ahí estaba el problema que dejaba a la población sin agua, le permitió abastecer de agua a su comunidad.

\section{Puentes entre prácticas y conocimientos de la comunidad e instituciones}

Desde las primeras reuniones con las instituciones, Dilia se convirtió en la mediadora entre dos comunidades con entendimientos diferentes del agua y el territorio, y con expectativas distintas. Dilia Beltrán recurrió a la traducción de las exigencias de las instituciones, quienes esperaban que parte de la infraestructura se construyera con fondos de la comunidad, con las prácticas y materialidades del campo. Al respecto, comenta: 
Muchos [de la comunidad] no estaban de acuerdo, pero promoví la cosa de una manera que entendieron. Cuando llegaba a las casas, la gente me decía: “yo no tengo plata, ¿cómo voy a pagar el agua?” y yo les decía: “¿Usted tiene gallinas?” "Sí.” "Tiene huevos, si tiene ovejas y está criando, va vendiendo por la carretera, y va echando a la alcancía esa plata". Les dije: "vayan ahorrando porque va a llegar el día que nos van a decir que tenemos que pagar, y cuando digan paguen, tenemos que tener la plata” (Dilia Beltrán, comunicación personal, 24 de noviembre de 2015).

Luego de la creación de un sistema de regulación y control del agua, siguiendo el Decreto 1575 y la Resolución 2115 del 2007, las instituciones encargadas del control de la calidad del agua intensificaron el control frente a las juntas administradoras de los $\mathrm{AC}$, esto sin saber qué instituciones serían responsables de apoyar los AC y las dificultades que estos tenían para cumplir con dichos requerimientos. Frente a este panorama, Flor Alba construyó un espacio de diálogo para solucionar el conflicto generado por la resistencia de la comunidad a la cloración del agua y a las medidas de control de las instituciones. Sobre esta situación, indica:

Yo le comentaba a la comunidad que siempre era prioritario el agua para consumo humano y que tocaba cumplir con calidad de agua y el tratamiento, y la comunidad nunca estaba de acuerdo porque pensaban que eso le hacía daño al ganado o a los cultivos. Entonces la Ing. Nubia de la empresa de acueducto trajo un veterinario, un agrónomo y a través de una presentación, mostró las bacterias que tenía el agua que estábamos tomando, y en la asamblea ella dio una explicación de que eso de la cloración no le hacía daño al ganado ni a los cultivos, y las consecuencias en la salud de la comunidad a largo plazo por las bacterias que consumíamos, era grave. Entonces ya la gente estuvo de acuerdo de que se tratara el agua, se firmó un acta, y ya con la autorización de la comunidad empezamos en julio de ese año a hacer tratamientos y nos ha funcionado (Flor Alba Díaz, comunicación personal, 25 de noviembre de 2015).

Dilia entiende estratégicamente el reconocimiento de la comunidad y, con su conocimiento 
de las necesidades de los habitantes de su vereda, puede negociar con las instituciones. Sus estrategias fueron invertir energía y tiempo en organizar a la comunidad, en explicarles a los funcionarios claramente las necesidades de la población y exigir su colaboración:

"Los de la CAR me decían: ¿Usted por qué pide tanto? Y yo respondía: ¿Por qué pide tanto, Doctor? Pero si no pedimos, hay es que llorar para la gente tenga lo que necesita". Él apenas se reía. Y me aprobaron entonces llevar el agua hasta El Destino y me dijeron: "Ahí tiene su agua que entra hasta la cocina" (Dilia Beltrán, comunicación personal, 24 de noviembre de 2015).

Esta última conversación nos permite ver la cercanía que construyó Dilia con los funcionarios, quienes informalmente se refirieron a su gestión como una petición. En esta negociación parece desaparecer el respaldo de un programa o política con procesos claros que garanticen los derechos de acceso al agua potable de toda la población rural. La construcción de las infraestructuras dependió entonces de la convicción y esfuerzo de lideresas y líderes y de la comunidad, donde la agencia permitió la configuración de unas dinámicas que son las bases del proceso de gestión al margen y en relación paralela a la normatividad y las políticas.

\section{Visiones del agua como un bien común, el cuidado del agua y la formalización de tarifas}

Flor Alba independizó al Acueducto de las dos Juntas de Acción Comunal de las veredas con el visto bueno de sus miembros, para superar los problemas en la toma de decisiones. Así, solicitó una personería jurídica como Asociación. Este fue el primer paso de varios que Flor Alba siguió con el fin de formalizar el acueducto de Aacupasa:

Eso para mí fue muy importante, haber podido quedar con Personería jurídica, haber actualizado la concesión de agua puesto que ya la habían dejado vencer, y pedir aumento de caudal para poder surtir mucha más gente y también mejorar las infraestructuras (Flor Alba Díaz, comunicación personal, 25 de noviembre de 2016).

Flor Alba cuenta cómo ella, a través de la legislación y del hecho de estar cumpliendo con la formalización exigida a los acueductos, reclamó a la CAR para que defendieran los derechos de la Asociación frente a la solicitud de una concesión de uso agropecuario de la misma fuente 
que capta el AC de Aacupasa. Flor Alba solicitó una visita técnica y se aseguró de contar con la presencia de la comunidad y otras instituciones distritales que habían apoyado al acueducto en su formalización. El conflicto se resolvió a favor de la Asociación de Usuarios Aacupasa. La CAR reconoció un error técnico de la funcionaria que había otorgado la concesión en una fuente que ya tenía una concesión que ocupaba toda su capacidad y agradeció no haber tomado una decisión desde el escritorio, usando y cuidando el agua más allá de la utilidad monetaria.

Por su parte, Dilia se refiere a la Quebrada Piedras Gordas:

Esa quebradita es bendita; le está dando agua a El Destino, le da al Ejército, el cual se independizó, y a Olarte" ... "Desde que nos entregaron el acueducto, nos dijeron que el agua no tiene necesidad de nada, porque es agua que viene por debajo de tierra y viene supremamente pura. Así que la consumimos cruda. La otra era que muchos querían que les diéramos agua gratis, iy no señor! aquí todos somos hijos de bendición, nada de eso, aquí todos tenemos que pagar el agua. Nunca me dejé, pero eso sí, bregué porque las cuotas fueran favorables. El Destino fue el acueducto más económico de la región (Dilia Beltrán, comunicación personal, 24 de noviembre de 2015).

También Ana Elfa recalca cómo para ella el agua no es una mercancía. Está de acuerdo con que se contabilice el agua para hacer un control de su consumo y llamar la atención de quienes la desperdician, pero se opone a que se cobre el agua por metro cúbico. Su relación con el agua y con el AC está sobre todo mediada por su uso cotidiano de otras fuentes, y por su trabajo comunitario.

Dilia resalta y reconoce el cuidado que algunas mujeres tienen con el agua, quienes luego de sufrir por conseguirla para realizar sus tareas diarias y tener que recorrer grandes distancias, cuidaban cada gota. También a través de su cargo como administradora del acueducto, controló el consumo y castigó el abuso de usuarios que la desperdiciaban. El primer castigado fue un usuario que dejó abierta el agua tanto que esta corrió y llenó el poso de un vecino. Dilia le pidió al fontanero de su acueducto que le suspendiera el agua a esta familia por un mes. A través de la gestión de tanques, buscó cuidar el recurso, no solo para garantizar su abastecimiento día por día, sino pensando en enfrentar tiempos de escasez, sequía y contaminación. 
Podemos resaltar que hasta aquí estas acciones de las mujeres las empoderan y las posicionan en sus comunidades, pero también hace que ellas tomen consciencia de sus capacidades de articular y movilizar a la comunidad en pos de objetivos relacionados con una gestión comunitaria del agua, haciendo conciencia de su importancia, del esfuerzo y el saber implicados en su captación y distribución, pero también en el manejo de su calidad y cantidad. Ello implica una toma de consciencia ecológica sobre el papel del agua y del trabajo humano para mantener su acceso y regulando el uso y protección.

\subsection{Mujeres: puente entre las instituciones públicas y los AC. Una historia convergente}

Entrelazamos aquí seis relatos independientes que se van hilando entre sí, dejando entrever los vínculos entre ellas, pero también con el agua, el territorio y sus habitantes. Vínculos que producen nuevos repertorios para la acción, a partir de la negociación que ellas hacen entre las propuestas que esgrimen los habitantes y los vacíos que las instituciones tienen para abordarlas. Entre otras, la acción de cada una de estas mujeres y sus decisiones intervienen en los siguientes procesos de gestión de los AC: la organización social para administrar y gestionar los acueductos, soporte humano para el sostenimiento de los $\mathrm{AC}$; el acompañamiento a los procesos de restauración de los ecosistemas que sostienen las fuentes que nutren los acueductos; la aprobación de las concesiones, proceso difícil pero fundamental para el uso del agua y sin el cual, no hay acuerdos que permitan el equilibrio y la distribución equitativa y regulada sobre su uso; el diseño de normativas que articulan la acción de las instituciones con las organizaciones sociales de base un eslabón fundamental; el establecimiento de los espacios de deliberación para hacer acuerdos colectivos, como las mesas de acueductos en cada localidad: Usme y Ciudad Bolívar; el fortalecimiento de las prácticas de uso eficiente y ahorro del agua mediante el apoyo a las comunidades para la elaboración de los PUEAS; la mejora de las prácticas que mantienen y hacen seguimiento autónomo para ofrecer agua de calidad, es un esfuerzo cotidiano que actúa desde las prácticas de potabilización (Palacio y Mejía, 2018).

Estas acciones encierran un entramado de experiencias y de sentidos que van emergiendo en sus narrativas. Entre ellas identificamos nociones que combinan conceptos técnicos, de las ciencias ambientales, la ingeniería, con la ética, la política y el derecho. Así mismo, vemos cómo ellas integran definiciones del territorio sur de Bogotá que apropian en su experiencia institucional y con el territorio como son: las de cuenca, el agua como bien común, la gestión 
comunitaria del agua, la justicia ambiental, el derecho al agua, agua de calidad para la salud humana, restauración ecológica para la conservación de los manantiales, entre otros.

En sus relatos observamos que la acción de estas mujeres tiene impacto sobre los repertorios de la acción de las comunidades, no a partir de una imposición pedagógica unidireccional, es decir, de un conocimiento que va de la institución a las comunidades, sino como un entramado de negociaciones mediante interacciones entre las funcionarias y de los habitantes del territorio, donde las funcionarias de manera explícita buscan interpretar las necesidades, los deseos y las maneras de hacer de las comunidades, para poner la institución y sus mandatos al servicios de las primeras. Estas negociaciones, a su vez, aportan estratégicamente a la apertura de posibilidades para que las comunidades continúen manejando sus AC.

A continuación, se bosquejan los perfiles y las trayectorias de estas mujeres, dando ejemplos de cómo cada una, desde su propia afiliación institucional y su narrativa, va proponiendo los puentes entre las lógicas comunitarias y las institucionales, para alcanzar una gestión del agua desde nuevos órdenes que reconocen el valor de los vínculos de las comunidades con el agua y el territorio.

\section{Primeras conexiones con lo rural y con el agua en un contexto de expansión urbana}

La abogada Gloria Narváez, durante su etapa como estudiante de derecho, participó apoyando a las comunidades de Ciudad Bolívar en dinámicas comunales y cívicas, entre 1992 y 1993, como la elección de las primeras Juntas Administradoras Locales (JAL) y el primer paro Cívico en Ciudad Bolívar. Las reivindicaciones del momento giraban alrededor de los servicios públicos domiciliarios, y la ampliación del Relleno de Doña Juana. A raíz del derrumbe en el relleno años después, surge la propuesta de la Mesa Inter-local de la Cuenca del río Tunjuelo liderada por FIDHAP $^{8}$, en alianza con ECOFONDO ${ }^{9}$ desde una perspectiva de ambientalismo popular urbano, que acompaña el proceso del Parque Entre Nubes. Este parque es un referente territorial que interconecta tres localidades: Usme, Ciudad Bolívar y Rafael Uribe Uribe. Esa experiencia nos sirve para entender que el río Tunjuelito es el cordón que teje el sur de la ciudad, integrando ocho localidades: Usme, Ciudad Bolívar, Tunjuelito, Bosa, Kennedy, Rafael Uribe Uribe, San Cristóbal y Sumapaz. Gloria comenta que a partir de preguntas como: ¿De dónde viene el agua? y ¿Dónde nace el río?, la Mesa Inter-local del río Tunjuelo construyó una propuesta de gestión social del

\footnotetext{
${ }^{8}$ FIDHAP Fundación para la Investigación y el Desarrollo del Hábitat Popular.

${ }^{9}$ Organización no gubernamental para acción política, ambiental y local.
} 
territorio alrededor del agua de la que hicieron parte: Dora Peña, Javier Reyes, Diego García, Deisy Ruíz, Melba Rubiano, Gladys Gómez, Alberto Gómez, Nelson Cruz, Miryam Mejía y otros líderes de Agrosolidaria. Miryam hizo parte en este momento del Acueducto y fue cercana con este proceso.

En ese mismo año Nancy Castellanos, ingeniera forestal, fue contratada por el alcalde local -(esposo y compañero de luchas de Miryam, funcionaria de la EAAB) para apoyar el tema de las reivindicadores de la comunidad en contra del Relleno de Doña Juana desde la Unidad Local de Asistencia Técnica (ULATA) de Usme, Nancy cuenta que estas localidades tenían una parte rural muy grande que el Distrito desconocía. Antes de la aprobación del primer POT ${ }^{10}$ de Bogotá en el año 2000, no había un desarrollo del componente ambiental en Planeación Distrital. Según Nancy, el concepto que se empezó a manejar por parte del DAMA ${ }^{11}$ fue el de restauración, el cual ha sido importante en la última década para recuperar las rondas de los nacimientos de las fuentes que hoy nutren los AC del sur: "hacia finales de la década de 1990, creando [crearon] un grupo de restauración que trabajaba directamente en coordinación con las ULATAS en el sur de Bogotá" (comunicación personal, 9 de noviembre, 2016).

En ese momento, las comunidades de las veredas del borde sur protestaron en contra de lo planteado en el POT al no recoger sus propuestas, y el DAMA les propuso a los líderes hacer una gira, en alianza con Parques Nacionales, para conocer las experiencias de agroturismo del Valle del Cauca. Desde entonces, los líderes de los Soches proponen la creación del Agroparque los Soches que quedó así definido en el POT.

La antropóloga Gloria Moreno fue contratada para diseñar una Agenda Ambiental para Suba (contrato DAMA-AVP ${ }^{12}$ en1993), experiencia que le permitió acompañar el componente social en obra de la construcción de los Acueductos en las veredas de Usme y Ciudad Bolívar entre 1998 y 2000. En ese trabajo tuvo la oportunidad de asistir a las reuniones que se hicieron con Planeación Distrital para el tema del POT, en las cuales, según Gloria, se definía lo rural como 'lo no urbano'. También comenta que, en Usme, la "mesa de ruralidad" y "la mesa de borde" estaban compuestas por líderes de la ruralidad, quienes trabajaban muy de la mano con la ULATA. Es a partir de estos trabajos que surge la propuesta dirigida a Planeación Municipal para que den prioridad presupuestal a los acueductos. Este proceso es paralelo a lo que estaba

\footnotetext{
${ }^{10}$ POT, Plan de Ordenamiento Territorial. Ley 388 de 1997.

${ }^{11}$ DAMA, Departamento Administrativo del Media Ambiente del Distrito hoy Secretaría de Ambiente.

12 AVP, Asociación para la Vivienda Popular.
} 
sucediendo con el Relleno en Ciudad Bolívar. Dentro de la licencia ambiental del prestador de ese entonces, se le obligó a financiar acueductos veredales para mitigar el daño (Gloria Moreno, comunicación personal, 22 de agosto, 2016).

\section{Acompañando la formalización de los $A C$}

Entre 1999 y 2005, período que Gloria Moreno llama 'institucionalización de los AC', hubo un asunto muy controversial al terminar las obras de infraestructura de los acueductos, sobre qué tipo de organización se gestaría para administrarlos. Al respecto, comenta:

Nuestro enfoque, desde la oficina de Gestión Comunitaria del EAAB era entender los AC como un modelo de gestión integral del agua, más que una infraestructura que ponía el énfasis en los tanques, tubos, desarenador, y todo eso. Para la gente, el AC era también un medio para distribuir agua para los animales, las vacas, para mejorar los abrevaderos, para el riego; por lo tanto, la gente decía 'yo quiero un acueducto, pero multipropósito (comunicación personal, 22 de agosto de 2016).

Por otro lado, estaba la perspectiva de hacer con la gente un proceso organizativo que les diera autonomía en el manejo de la infraestructura, desde una lógica solidaria. La gente quería que cada vereda supliera la necesidad del agua a partir de una red de vecinos, sobre todo esto se sentía en las épocas secas. Adicionalmente, la gente empezó a entender, desde los trabajos de salud pública, que el agua que tomaban no era buena, y empezaron a entender que podían hacer procesos de desinfección de distintas maneras. De ello emergió otra controversia sobre la protección de las fuentes de agua y la propiedad de los predios donde estaban las bocatomas de los AC.

De allí nació la idea de fundar la Red Territorial de AC de Bogotá y Cundinamarca (RETACO), que se formalizó en 2010. De esa lectura crítica identificamos como central que no había una política y una normativa específica para acueductos veredales. Después de hacer una búsqueda con el apoyo de abogados, se encontró que ninguna alcaldía tenían claro el tema:

Encontré unas abogadas muy pilas en la Alcaldía Mayor que intentaron rastrear unas pistas en el esquema del Estatuto Orgánico de Bogotá, pero cuando ya estaban a punto de lograr algo, cambiaron la abogada, y después tumbaron la alcaldesa. Realmente el esfuerzo que se hizo, nunca rindió frutos: nadie tenía claro jurídicamente cómo hacerlo (Gloria 
Moreno, comunicación personal, 22 de agosto de 2016).

\section{Sensibilización: ir más allá de lo policivo}

Norvira Soto, trabajadora social, retomó el acompañamiento que venía haciendo Gloria Moreno desde la Dirección de Gestión Comunitaria de la EAAB en 2006. La ruta de gestión de la EAAB giraba en torno a identificar las fallas técnicas y asegurarse de que se hiciera el trabajo de la potabilización. Sin embargo, estos acueductos tenían mucha dificultad con los temas administrativos y financieros. Ella acompañó el proceso en trece acueductos de Sumapaz donde nada sucede sin que pase por el Sindicato Agrario:

Tuvimos la fortuna, en ese entonces, de tener una alcaldesa en Sumapaz. Magnolia. Ella fue una mujer que le dio presencia a la institucionalidad y reconocimiento a las comunidades. En los encuentros asamblearios, después de mucha persistencia, logramos espacios, para los encuentros de acueductos veredales. Hicimos entonces talleres de fortalecimiento organizativo y temas legislativos; ellos estaban metidos en una "vaca loca", tenían unos compromisos enormes, sin siquiera conocer la ley. Adicionalmente, se logró trascender ese papel policivo que controlaba los AC mediante el IRCA ${ }^{13}$, acordando con el hospital Nazareth un trabajo de sensibilización y capacitación para lograr la comprensión por parte de la comunidad y de sus organizaciones sobre la importancia del agua potable en el tema de la salud (Norvira Soto, comunicación personal, 28 de junio de 2016).

\section{¿Cumplir la norma o derecho al agua?}

Alix Montes, socióloga, empezó en el área Social de la Dirección Regional de Bogotá -la Calera, de la CAR en 2009. Había trabajado en la Regional Sumapaz. Su función, al llegar, fue realizar el seguimiento de los acueductos rurales de la jurisdicción de esta oficina. Ella hace hincapié que su guía es la norma, pues ella no hace las cosas por iniciativa personal sino como funcionaria y servidora pública. En particular, su función es asegurar que las solicitudes de concesión para el

\footnotetext{
${ }^{13}$ IRCA, índice para la medición de la calidad del Agua.
} 
uso del agua queden bien diligenciadas:

Aquí en mi oficina se les entrega su formulario, se les pide los diseños de las obras para captación del agua, el estado sanitario del recurso hídrico que lo expide la Secretaría de Salud, el censo de usuarios, el caudal que están solicitando, entre otras. Cuando se cumplen los requisitos, hay tres meses para la publicación del permiso" (Alix Montes, comunicación personal, 14 de octubre de 2015).

Por su parte, Zaida Navarro, administradora ambiental, cuenta que la Defensoría del Pueblo, a través de la Delegada de Servicios Públicos, había empezado a hacer un seguimiento a la problemática del Relleno Doña Juana a finales de 2009. Al respecto, cuenta:

Fuimos a Mochuelo Bajo, por solicitud de la comunidad para hacer el seguimiento al cumplimiento del informe que se hizo con el derrumbe. En esas reuniones, sin embargo, la gente no nos hablaba del Relleno, sino de los acueductos. Había un problema en Mochuelo con el acueducto. Entonces, les propusimos acudir al Distrito, a las distintas instituciones competentes. Pero la comunidad nos dijo que ya habían ido y no habían conseguido resolver el problema. Retomando las peticiones de la comunidad, llamamos a la Superintendencia, y nos dijo que no era su función. Llamamos a Supersolidaria, pero esta nos dijo que ya había mandado concepto a la Superservicios. Entonces fuimos a la Alcaldía Local que nos respondió a su vez que no manejaban problemas de AC, y nos sugiere ir a la Superintendencia de Personas Jurídicas del Distrito. Allá nos dijeron ¿AC? ¿quiénes son esos? En resumen, nos hicieron el 'pinponeo', como dice la comunidad para denominar la remisión que las instituciones hacen a las comunidades una oficina a otra. Y yo reflexioné... ¡Si eso se lo hacen a la Defensoría del Pueblo, ¿qué es lo que le hacen a la Comunidad? De esta manera, retomamos el tema del 'derecho humano al agua', para aclarar cuáles son esas competencias de las instituciones sobre los AC. Asistimos a las reuniones de los AC y vimos que había otros problemas. Así elaboramos el informe (Zaida Navarro, comunicación personal, 30 de marzo, 2016. 


\section{Coordinar y colaborar en la gestión de los AC en Bogotá}

Gloria Narváez entró a la Secretaría de Hábitat en 2010. Desde allí recogió las propuestas de RETACO sobre la necesidad de una mesa interinstitucional coordinada para tratar los temas de los AC: infraestructura, organización, administración y calidad de agua, solicitud que fue consignada en el informe de la Defensoría del Pueblo.

Cuando inicié mi labor jurídica en la Secretaria de Hábitat, muchas entidades intervenían en las diferentes problemáticas de $\mathrm{AC}$, pero no se resolvía nada. La Superintendencia de Servicios Públicos, por su parte tenía mecanismos de acercamiento a los pequeños prestadores, pero las Asociaciones de Acueductos sabían que una vez aceptaran ese mecanismo y se formalizaran, tendría consecuencias sobre su modelo comunitario. Adicionalmente, en la oficina jurídica de la Secretaría de Hábitat no entendían que la prestación de un servicio público puede ser público, privado, mixto o comunitario.

Entonces, me di a la tarea de dar el soporte jurídico para el diseño del Decreto 522 desde la Constitución Política de Colombia. Encontramos el Artículo 365 que dice que los servicios públicos pueden ser prestados por el Estado, directa o indirectamente, por particulares o por comunidades organizadas; y complementamos con las sentencias de la Corte Constitucional y desde otras experiencias de colegas que estaban trabajando como Penca de Sábila en Medellín. El Código de Recursos Naturales, por su parte, reconocía la construcción de asociaciones de usuarios del agua. Los usuarios del agua se convertían en un mecanismo de poder prestar el servicio, y ¿quién eran los acueductos en Bogotá? Usuarios del agua. ¡Eureka! Es así que Clara López, como Alcaldesa Mayor Encargada, a finales de 2011, retomando nuestra propuesta sobre el derecho humano al agua, incluye entre sus decretos el mínimo vital para la gente en condición de vulnerabilidad en zonas periurbanas y la gestión comunitaria del agua con el Decreto 552 de 2011 que instaura la 
Mesa Interinstitucional para los AC (Gloria Narváez, comunicación personal, 25 de noviembre de 2015).

Al respecto, Alix Montes también comenta que "A través del requerimiento de los entes de control de la CAR, todas las instituciones hicimos una mesa técnica para dar una respuesta interinstitucional" (comunicación personal, 14 de octubre de 2015).

Miryam Mejía, psicóloga social, y Nubia León. ingeniera química, la una desde la Dirección de Gestión Comunitaria y la otra desde Ingeniería Especializada de la EAAB colaboran desde 2012 hasta hoy, haciendo el acompañamiento técnico y social a los AC en el marco de un proyecto de investigación y gestión colaborativa del agua, donde ellas con Gloria F. de Gestión Humana, proponen formular un proyecto de investigación donde proponen que Dolly Palacio, trabajadora social, profesora titular de la Facultad de Ciencias sociales de la Universidad Externado de Colombia, lidere dicho proyecto en convenio con la RETACO y Agropolis S.A, donde Marcela Arrieta participó primero con su tesis de maestría y después con su tesis doctoral. Trabajamos con los líderes de la gestión comunitaria del agua desde la identidad campesina en el sur de Bogotá (Palacio et al., 2018). Ellas, con nuestra colaboración, fortalecemos las mesas de AC en Usme, Ciudad Bolívar y Sumapaz. Durante los últimos ocho años, nos reunimos, recogiendo voces y necesidades, programamos actividades que van siendo desarrolladas por las tres partes (empresa, academia y organizaciones sociales). También implementamos un sistema de formación de fontaneros, y grupos de jóvenes escolarizados en monitoreo de calidad de agua y buscamos resolver mediante procesos colaborativos, los problemas técnicos y de infraestructura, organizativos y de conciencia colectiva frente al territorio y el agua. En este proceso ha sido central generar que las comunidades sean garantes de la administración de sus propios vínculos con el agua, los ecosistemas y las infraestructuras asociadas.

\section{A manera de conclusión: pistas para reconocer los nuevos órdenes, donde lo femenino y el agua cuentan en la gestión del territorio}

Las trayectorias de estas mujeres se construyen en el territorio, en la cotidianidad de sus tareas. Estas trayectorias les proponen trabajos conjuntos, diálogos y negociaciones, colaboraciones y aprendizajes. Cada una de ellas sigue a su modo y desde sus distintas posibilidades, aportando a este proceso socioambiental y a muchos procesos parecidos en otros territorios. Su vida se ha 
volcado en una misión a largo plazo sobre temas del cuidado del agua, de los ecosistemas, del territorio y su defensa frente a procesos que, como la expansión urbana, han sido letales para muchas de las fuentes de agua que son la base de la vida en los territorios.

Se hace evidente cómo los procesos de construcción de los AC están marcados, no solo por el proceso de modernización y la expansión urbana, sino por una fuerte experiencia de organización y conciencia ecológica por parte de sus participantes. A partir de los testimonios de lideresas comunitarias representantes de los acueductos, vemos como sortean momentos de incertidumbre, y en ocasiones, sin muchas seguridades más que su convencimiento y apoyo de las comunidades, negocian con los actores institucionales. Recibir, en este caso, las infraestructuras del sistema de abastecimiento y capacitaciones es un gran trabajo de liderazgo y persistencia.

Las lideresas se enfrentan también a una formalización que cuando es aplicada como una norma, impone un orden y una visión unívoca sobre el agua, que disloca los vínculos múltiples de las comunidades con el agua, fragmentándola. Estas mujeres han sido las garantes tejedoras de los vínculos comunitarios con los procesos formales que proponen las instituciones desde sus competencias. Lo que hace de su labor, por un lado, un trabajo de mediación y construcción de puentes entre el Estado y sus ciudadanos, mientras contribuye, por otro lado, con el cuidado del agua, de las fuentes y sus ecosistemas asociados.

Estas mujeres con sus prácticas con el agua, construyen nuevas materialidades y sentidos, usando la formalización como una alianza estratégica para cambiar las estructuras de poder, siendo ellas las que exigen a las instituciones el cumplimento de sus derechos del acceso al agua. Así, la norma se convierte en mediación traducida a favor de las lógicas comunitarias.

Es así como frente al orden hegemónico regularmente impartido desde las instituciones, que pone condiciones a las comunidades bajo dinámicas que usan una lógica contable desde las reglas de la administración moderna que se basa en una racionalidad monetizada, las lideresas traducen estas lógicas para sus comunidades, posibilitando que estas puedan cumplir con las condiciones impuestas desde sus propios términos. Mediante negociaciones con las comunidades y las instituciones, las lideresas ponen este orden hegemónico a su servicio.

Por su parte, el orden hegemónico de las instituciones aprovecha la falta de claridad de un procedimiento para controlar a las comunidades. Pero las lideresas han usado esta incertidumbre 
a su favor flexibilizando sus rutinas para seguir construyendo puentes que hagan viable el mantenimiento de estos acueductos, base de la sostenibilidad territorial.

Todos estos elementos se constituyen en una pista para comprender que estos entrecruces son un tejido que al evidenciarse, se puede convertir en claves para un ecofeminismo consciente, activo y situado, que parte de la fuerza de la agencia de las mujeres y los vínculos que ellas reconocen, vitalizan y sostienen, creando vías para la defensa del territorio y el agua.

\section{Referencias bibliográficas}

Arriagada, Evelyn., y Zambra, Antonia. (2019). Apuntes iniciales para la construcción de una Ecología Política Feminista de y desde Latinoamérica. Polis, 18(54), 12-26. doi: 10.32735/S0718-6568/2019-N54-1399

Arrieta, Marcela. (2018). El papel del agua en la relación del borde sur y Bogotá. En Dolly Palacio, María Van der Hammen, Amparo de Urbina (Eds.), Fuentes vivas en el borde. Investigación y experiencias colaborativas para la gobernanza de un sur sostenible en Bogotá (pp. 813)[e-book]. Bogotá: Universidad Externado de Colombia. Recuperado de https://bdigital.uexternado.edu.co/micrositios/fuentesvivasagua/contenidos/1_area_estudi o/pdf/capitulo1_3.pdf

Beall, Jo. (1995). La construcción social del género en el Tercer Mundo. En Ana Muñoz y Lucy Wartenberg (Comps.), Planeación con perspectiva de género (pp. 13-98). Bogotá: Universidad Externado de Colombia, Consejería Presidencial para la Juventud, la Mujer y la Familia y el Consejo Británico.

Celiberti, Lilian. (Coord.). (2019). Las bases materiales que sostienen la vida. Perspectivas ecofeministas. Montevideo: Unión Europea, Cotidiano Mujer - Colectivo Ecofeminista Dafnias. Recuperado

de http://www.cotidianomujer.org.uy/sitio/attachments/article/2178/LasBasesMaterialesQue SostienenLaVida\%20-\%20Perspectivas\%20Ecofeministas.pdf\#page=48

Del Castillo, Juan., Urrea, Tatiana, y Montaña, Jimena. (2011). Usme, historia de un territorio. Bogotá: Alcaldía Mayor de Bogotá, Metrovivienda.

Cuervo, Otilia, van der Hammen, María Clara, y Morales, Diana. (2018). Moviendo procesos sin descanso. Una experiencia de vida en defensa de un territorio y su desarrollo social: Otilia 
Cuervo de la vereda La Requilina en Usme, localidad de Bogotá, D.C. En Dolly Palacio, María Van der Hammen y Amparo de Urbina (Eds.), Fuentes vivas en el borde. Investigación y experiencias colaborativas para la gobernanza de un sur sostenible en Bogotá (pp. 13-41). Bogotá: Universidad Externado de Colombia. Recuperado de https://bdigital.uexternado.edu.co/micrositios/fuentesvivasagua/contenidos/3_actores/pdf/ capitulo3_1.pdf

Delbene-Lezama, Lucía. (2019). Una mirada ecofeminista a la gestión del agua en Uruguay. En Lilian Celiberti (Coord.), Las bases materiales que sostienen la vida. Perspectivas ecofeministas (pp. 47-98). Montevideo: Unión Europea, Cotidiano Mujer - Colectivo Ecofeminista Dafnias. Recuperado de http://www.cotidianomujer.org.uy/sitio/attachments/article/2178/LasBasesMaterialesQue SostienenLaVida\%20-\%20Perspectivas\%20Ecofeministas.pdf\#page $=48$

García, Catalina, y Cortés, Nadia. (2018). Bordes urbanorurales en los instrumentos de ordenamiento territorial. ¿hacia dónde y cómo crecer? En Dolly Palacio, María Van der Hammen y Amparo de Urbina (Eds.), Fuentes Vivas en el Borde. Investigación y Experiencias Colaborativas para la gobernanza de un sur sostenible en Bogotá (pp. 7-11). Bogotá: Universidad Externado de Colombia. Recuperado de https://bdigital.uexternado.edu.co/micrositios/fuentesvivasagua/

Haraway, Dona. (1995). Ciencia, cyborgs y mujeres. La reinvención de la naturaleza. Madrid: Cátedra.

Jaramillo, Samuel. (2014). Precios inmobiliarios de la vivienda en Bogotá 1970-2013. Documentos CEDE. Centro de Estudios sobre Desarrollo Económico, 17, 1-90.

Kaika, Maria. (2005). City of Flows, Modernity, Nature and the City. Nueva York, Oxon: Routledge.

Latour, Bruno. (2017). Cara a Cara con el Planeta. Una nueva mirada sobre el cambio climático alejada de las proposiciones apocalípticas. Buenos Aires: Siglo XXI.

Neimanis, Astrida. (2017). Bodies of Water. Posthuman Feminism Phenomenology. Londres: Bloomsbury Academic Publishing.

Ojeda, Diana. (2012). Género, naturaleza y política: los estudios sobre género y Medio Ambiente. HALAC, 1(1), 55-73. 
Osorio, Julián. (2007). El río Tunjuelo en la historia de Bogotá, 1900-1990. Bogotá: Secretaría de Cultura, Turismo de la Alcaldía de Bogotá.

Osorio, Julián. (2008). La historia del agua en Bogotá: una aproximación bibliográfica sobre la cuenca del río Tunjuelo en el siglo XX. Memoria y Sociedad, 12(25), 107-116.

Palacio, Dolly, y Mejía, Miryam. (2018). Relatos comunitarios sobre la historia de los acueductos del borde sur. En Dolly Palacio, María Van der Hammen y Amparo de Urbina (Eds.), Fuentes Vivas en el Borde. Investigación y experiencias colaborativas para la gobernanza de un sur sostenible en Bogotá (pp. 23-67). Bogotá: Universidad Externado de Colombia. Recuperado de https://bdigital.uexternado.edu.co/micrositios/fuentesvivasagua/

Palacio, Dolly, Van der Hammen, María Clara, y De Urbina, Amparo. (2018). Fuentes Vivas en el Borde. Investigación y experiencias colaborativas para la gobernanza de un sur sostenible en Bogotá. Bogotá: Universidad Externado de Colombia. Recuperado de https://bdigital.uexternado.edu.co/micrositios/fuentesvivasagua/

Palacio, Germán, y Rouillón, Manuel. (2008). La urbe modernizada. Elementos para una historia ambiental de Bogotá (1920-1980). En Germán Palacio (Ed.), Historia ambiental de Bogotá y La Sabana, 1850-2005 (pp. 124-168). Bogotá: Universidad Nacional de Colombia/IMANI.

Preciado, Jair, Leal, Roberto, y Almanza, Cecilia. (2005). Historia ambiental de Bogotá, Siglo XX. Elementos históricos para la formulación del Medio Ambiente Urbano. Bogotá: Universidad Distrital Francisco José de Caldas.

Puleo, Alicia. (2011). Ecofeminismo para otro mundo posible. Madrid: Editorial Cátedra Universidad de Valencia.

Puleo, Alicia. (2019). Claves Ecofeministas. Para rebeldes que aman a la Tierra y a los animales. España: Editorial Plaza \& Valdés.

Rocheleau, Dianne, Thomas-Slayter, Barbara, y Wangari, Esther. (1996). Feminist Political Ecology. Londres, Routledge.

Rocheleau, Dianne, Thomas-Slayter, Barbara, y Wangari, Esther. (2004). Género y ambiente: una perspectiva de la ecología política feminista. En Verónica Vázquez y Margarita Velázquez. (Coords.), Miradas al futuro (pp. 343-371). México: PUEG, CRIM, CP.

Rodríguez, Juan. (2003). El agua en la historia de Bogotá. Bogotá: Villegas Editores. 
Sánchez, Vladimir. (2016). Un río del Sur. Desigualdad urbana en Bogotá a mediados del siglo $X X$. Bogotá: Universidad de Los Andes.

Shiva, Vandana. (1997). Economic Globalization, Ecological Feminism, and Sustainable Development. Canadian Woman Studias, Les Chiers de la Femme, 17(2), 22-27. Recuperado de https://cws.journals.yorku.ca/index.php/cws/article/viewFile/8884/8061

Siderac, Silvia. (2019). Acuerpándonos para tejer pluralidades. Entrevista a Lorena Cabnal. Entramados: Educación y Sociedad, (6), 9-19.

Ulloa, Astrid. (2015). Environment and Development: Reflections from Latin America. En Tom Perreault, Gavin Bridge y James McCarthy (Eds.), The Routledge Handbook of Political Ecology (pp. 320-331). Nueva York: Routledge.

Ulloa, Astrid. (2016). Feminismos territoriales en América Latina: defensas de la vida frente a los extractivismos. Nómadas, (45), 123-139.

Van der Hammen, María Clara, Cano, Claudia, y Palacio, Dolly. (2015). Insumos para el debate sobre la delimitación del complejo de Páramos de Cruz Verde - Sumapaz. Bogotá: Universidad Externado. Instituto Humboldt, Fondo de Adaptación.

Van der Hammen, María Clara, Morales, Diana, Gómez, Patricia, Rodríguez, Javier, Cuervo, Otilia, Aya, Diana, y León, María Antonia. (2018). Historia ambiental del sur de bogotá. ¿Para qué una historia ambiental? En Dolly Palacio, María Van der Hammen y Amparo de Urbina (Eds.), Fuentes vivas en el borde. Investigación y experiencias colaborativas para la gobernanza de un sur sostenible en Bogotá (pp. 10-13). Bogotá: Universidad Externado de Colombia. 